\title{
Human Acellular Amniotic Matrix with Previously Seeded Umbilical Cord Mesenchymal Stem Cells Restores Endometrial Function in a Rat Model of Injury
}

\author{
Shan Wang $\mathbb{D}$, ${ }^{1,2}$ Cheng Shi $\mathbb{D},{ }^{1}$ Xiaohui Cai $\mathbb{D},{ }^{2}$ Yanbin Wang $\mathbb{D},{ }^{1}$ Xi Chen $\mathbb{D},{ }^{1}$ \\ Hongjing Han $\mathbb{D}^{1},{ }^{1}$ and Huan Shen $\left(\mathbb{1}^{1}\right.$ \\ ${ }^{1}$ Peking University People's Hospital, Reproductive Medicine Center, Beijing 100044, China \\ ${ }^{2}$ Beijing Friendship Hospital, Capital Medical University, Department of Obstetrics and Gynecology, Beijing 100050, China \\ Correspondence should be addressed to Hongjing Han; han_hhj@126.com and Huan Shen; shenhuan418@126.com
}

Received 14 February 2021; Revised 24 June 2021; Accepted 3 August 2021; Published 6 September 2021

Academic Editor: Tomasz Brzozowski

Copyright (C) 2021 Shan Wang et al. This is an open access article distributed under the Creative Commons Attribution License, which permits unrestricted use, distribution, and reproduction in any medium, provided the original work is properly cited.

Background. Abnormal endometrial repair after injury results in the formation of intrauterine adhesions (IUA) and a thin endometrium, which are key causes for implantation failure and infertility. Stem cell transplantation offers a potential alternative for some cases of severe Asherman's syndrome that cannot be treated with surgery or hormonal therapy. Umbilical cord-derived mesenchymal stem cells (UCMSCs) have been reported to repair the damaged endometrium. However, there is no report on the effects of UCMSCs previously seeded on human acellular amniotic matrix (AAM) on endometrial injury. Methods. Absolute ethanol was injected into rat uteri to damage the endometrium. UCMSCs previously seeded on AAM were surgically transplanted. Using a variety of methods, the treatment response was assessed by endometrial thickness, endometrial biomarker expression, endometrial receptivity, cell proliferation, and inflammatory factors. Results. Endometrial thickness was markedly improved after UCMSC-AAM transplantation. The expression of endometrial biomarkers, namely, vimentin, cytokeratin, and integrin $\beta 3$, in treated rats increased compared with untreated rats. In the UCMSC-AAM group, the VEGF expression decreased, whereas that of MMP9 increased compared with the injury group. Moreover, in the AAM group, the MMP9 expression increased. The expression of proinflammatory factors (IL-2, TNF $\alpha$, and IFN- $\gamma$ ) in the UCMSC-AAM group decreased compared with the untreated group, whereas the expression of anti-inflammatory factors (IL-4, IL-10) increased significantly. Conclusions. UCMSC transplantation using AAM as the carrier can be applied to treat endometrial injury in rats. The successful preparation of lyophilized AAM provides the possibility of secondary infectious disease screening and amniotic matrix quality detection, followed by retrospective analysis. The UCMSC-AAM complex may promote the better application of UCMSCs on the treatment of injured endometrium.

\section{Introduction}

Endometrial injury, which affects endometrial thickness and involves IUA formation, is a cause of amenorrhea, implantation failure, and infertility [1], which have been on the rise due to the continuous increase in the rates of abortions and hysterectomies in China [2,3]. Presently, IUA formation is treated with estrogen-based intrauterine devices (IUDs) to promote endometrial growth and balloons to prevent IUA recurrence. However, IUDs can adversely affect endometrial repair as well as cause inflammation and infertility [4]. To increase the thickness of the endometrium, sildenafil and granulocyte colony stimulating factor (G-CSF) are applied [5]. However, these entities have very limited effects on the restoration of endometrial function, especially in cases of severe basal layer damage $[6,7]$.

With advancements in tissue engineering, mesenchymal stem cells (MSCs) have been used to repair and regenerate tissues [8]. The basal layer, which lies beneath the epithelial layer, supplies stem and progenitor cells for the production of new functional layers in each menstrual cycle $[9,10]$. These cells were reported to express mesenchymal-like stem 
cell markers and show mesodermal differentiation characteristics [11-13]. Unfortunately, iatrogenic curettage results in the destruction of the stem cell niche, and hence, in the loss of stem cells and in the failure of endometrial regeneration. Investigators have used donor-derived bone marrow mesenchymal stem cells (BMMSCs) to repair endometrial damage, essentially triggering the expression of endometrial cell markers, increasing endometrial thickness, increasing blood vessel formation, and improving endometrial receptivity [14-17]. Other studies have demonstrated that tail vein injection of UCMSCs increased the expression of HOXA10, a biomarker of endometrial receptivity, and improved endometrial function in mice [18-20].

Studies have shown that transplanation yields different effects $[21,22]$. An ideal transplantation method should meet four conditions as follows: (i) a relatively high concentration of MSCs should accumulate in the injured area, (ii) MSCs should be evenly distributed within the endometrium, (iii) MSCs should effectively adhere to the endometrium and not be squeezed out of the uterine cavity, and (iv) there should be no biological toxicity and immunogenicity. To meet these requirements, MSCs should be seeded onto a scaffold, which then be transplanted.

Human amniotic membrane (AM) is a biofilm derived from the inner layer of the human placenta. It has been used in tissue repair for over a century and has many advantages such as its similarity with the three germ layers compared with synthetic materials [23]. The pores on AM can allow water and some small molecules to pass through; although, it is difficult for inflammatory cells to infiltrate [24, 25]. AM expresses IL-1 receptor antagonist (inhibits the expression of proinflammatory factors), IL-10 (inhibits the secretion of inflammatory factors), IL-4, IL-6, IL-8, and protease inhibitors [26]. In addition, AM secretes a variety of growth factors and cytokines, including platelet-derived growth factor AA (PDGF-AA), transforming growth factor $\beta 1$ (TGF $\beta 1$ ), vascular endothelial growth factor (VEGF), and fibroblast growth factor 2 (FGF-2). It was also reported that AM can promote the proliferation of endothelial cells and the expression of growth factors and facilitate angiogenesis [27]. Therapeutic effect of Foley balloon with or without AM on IUA was compared, and menstrual recovery, readhesion, and the pregnancy rate in the AM+Foley balloon group were better than Foley balloon alone, suggesting that the AM acts as a biologically active isolator and is valid on the treatment of endometrial adhesions [28].

Despite the advantages of FAM (fresh AM), FDAAM (freeze-dried acellular amniotic membrane) should be used instead of FAM to decrease the risk of infectious diseases. AAM refers to the biological material composed of the basal layer and dense layer of AM [29]. It has characteristics of nonimmunogenicity, a 3D fiber-like structure, good biocompatibility, and natural degradation [30,31]. Decellularization and lyophilization will decrease the levels of cytokines and other bioactive factors, while culturing UCMSCs on AAM can make up for this deficiency. If FDAAM is used as carrier, adhesions can be prevented under the premise of ensuring safety. At the same time, it provides a $3 \mathrm{D}$ structure for the attachment, growth, and migration of UCMSCs in vivo, fur- nishing a high density of these grafting cells in per unit area. In addition, certain cytokines secreted by UCMSCs can promote cell proliferation and regulate inflammation, which can promote repair of endometrial damage. Therefore, the present study constructed the UCMSC-AAM complex and detected its ability to regulate inflammation response and restore injured endometrium. The safety of AAM as cell carrier was also confirmed. There has been no study reported about MSC using AAM as carrier to cure endometrial injury diseases yet. Our results may provide insights on the innovative application of AAM as cell carrier and biofilm in tissue damage diseases and cell replacement therapy.

\section{Materials and Methods}

2.1. Ethics. All surgical procedures were performed on 6-8week-old female Sprague Dawley rats (SPF level, Beijing Vital-River Laboratory Animal Technology Company, China) weighing 220-260 g. Four rats were housed per cage at a room temperature of $23-25^{\circ} \mathrm{C}$, a relative humidity of $40-60 \%$, and a light/dark cycle of $12 \mathrm{~h} / 12 \mathrm{~h}$. All rats had free access to food and water. All animal procedures were approved by the Laboratory Animal Ethics Committee of Peking University People's Hospital and adhered to National of Institutes of Health guidelines. All researchers involved in animal experiments were licensed by the Beijing Association on Laboratory Animal Care. The acquisition of amniotic membranes from human placentas was approved by the Ethical Review Board Committee of Peking University People's Hospital with prior written informed consent.

2.2. Acquisition of Human Placentas. Mothers who tested negative for the human immunodeficiency virus, syphilis, hepatitis $\mathrm{B}$ virus, and hepatitis $\mathrm{C}$ virus were registered. Human placentas were acquired from three mothers who underwent cesarean sections with no complications, and amniotic membranes were placed into containers containing saline under sterile conditions with no remaining villi.

2.3. Preparation of AAM. This experiment was performed in $10 \mathrm{~cm}$ dishes (Corning, USA) in a biological safety cabinet. AM was treated with $100 \mathrm{U} / \mathrm{mL}$ of penicillin and $100 \mu \mathrm{g} / \mathrm{mL}$ of streptomycin (Thermo Fisher Scientific, USA) for $30 \mathrm{~min}$ and rinsed with sterile saline. Thereafter, it was treated with $0.1 \%$ Triton X-100 (Sigma-Aldrich) and incubated in a shaking incubator at $37^{\circ} \mathrm{C}$ for $36 \mathrm{~h}$. AM was rinsed with saline and treated with $2.5 \%$ trypsin-EDTA (Thermo Fisher Scientific) at $37^{\circ} \mathrm{C}$ for $4 \mathrm{~h}$. A cell scraper was used to separate the epithelial cell layer and the spongy layer. Tissues were cut into 1 $\mathrm{cm} \times 2 \mathrm{~cm}$ fragments. A portion of the FAAM was cryopreserved in $0.1 \%$ glycerol and stored at $-20^{\circ} \mathrm{C}$.

2.4. Cell Culture and Reagents. UCMSCs were obtained from the Beijing Stem Cell Bank, which is certified by National Institutes for Food and Drug Control (Report No: SH201401380), and the Karyotype, specific surface antigens, and differentiation results were showed in Figure S1. Cells were established from umbilical cord obtained from a healthy puerpera who underwent a cesarean section. Cells were cultured in $6 \mathrm{~cm}$ culture dishes in $\alpha$-MEM medium 
(Thermo Fisher Scientific) containing 10\% fetal bovine serum (FBS) (Thermo Fisher Scientific), $100 \mathrm{U} / \mathrm{mL}$ penicillin, and $100 \mu \mathrm{g} / \mathrm{mL}$ streptomycin. Cells were passaged with $0.25 \%$ Trypsin-EDTA and cultured at $37^{\circ} \mathrm{C}$ in an incubator containing $5 \% \mathrm{CO}_{2} / 95 \%$ air. After incubation for $12 \mathrm{~h}$, UCMSCs were labeled with GFP and sorted by flow cytometry. Cells were passaged for further analysis after 23 days. Cells from early passages (p3-p5) were used in the following experiments.

\subsection{Preparation and Detection of the UCMSC-AAM Complex}

2.5.1. Preparation of the UCMSC-AAM Complex. FDAAMs with the same size $(1 \mathrm{~cm} \times 2 \mathrm{~cm})$ were submerged in $0.5 \mathrm{~mL}$ of PBS in a $6 \mathrm{~cm}$ dish and flattened with forceps. The dish was sealed and placed in an incubator at $37^{\circ} \mathrm{C}$ overnight and then in a refrigerator at $4^{\circ} \mathrm{C}$ for $4 \mathrm{~h}$, and FDAAM will firmly attached to the bottom of dish, which should be used during 1 week. Place the dish at room temperature for $1 \mathrm{~h}$ and aspirate the remaining liquid on the lid before use. Thereafter, UCMSCs were counted before the same number $\left(1 \times 10^{6}\right)$ of cells that were seeded in each dish, shake carefully to make cells evenly distributed, and cultured at $37^{\circ} \mathrm{C}$ in an incubator containing $5 \% \mathrm{CO}_{2} / 95 \%$ air, with daily changes of medium. Cells were stained with DAPI on day 3. UCMSC-AAM complex was harvested on day 5 , at the accurate same time when cells were left to incubate, to maintain the consistency of cell incubation time between batches.

2.5.2. Comparison of Carrying Quantity. The same number of UCMSCs was seeded on FAAM and FDAAM, followed by culturing under the same conditions. On day 3 , when the cell confluency was approximately 70-80\%, FAAM and FDAAM were washed three times with PBS and digested with $0.25 \%$ trypsin for $5 \mathrm{~min}$. Cells were collected and counted.

2.5.3. Scanning Electron Microscopy. On day 3, FAAM and FDAAM were fixed in $2.5 \%$ glutaraldehyde overnight, washed three times in PBS (15 min each time), and treated with $1 \%$ osmic acid for 2-4h. Specimens were dehydrated in an alcohol series, dried, and immersed in isoamyl acetate overnight. Specimens were coated with gold before scanning electron microscopy (FEI, inspect s50).

\subsection{Animal Experimental Design}

2.6.1. Group and Treatment. A total of 48 rats in the same phase of estrus cycle were randomly divided into four groups as follows: endometrial injury group, AMM transfer after injury group, UCMSC-AAM transfer after injury group, and normal group $(n=12$ for each group, 6 were sacrificed at the estrus phase three cycles after surgery for histological and PCR analyses, and the others were mated for fertility tests at four cycles after surgery).

2.6.2. Wright and Giemsa Stain Assay. Totally, 60 rats were selected to assess the changes of various types of cells in vaginal smears. Vaginal smears were performed on at 9:00 a.m. for 15 consecutive days using lavage method. $10-20 \mu \mathrm{L}$ of lavage fluid was spread evenly on the glass slide and wait for dry naturally. Wright and Giemsa staining solution (G1020, Solarbio, China) was used following the instruction.

2.6.3. Establishment of the Rat Endometrial Injury Model. All surgical procedures were performed under sterile conditions. All rats $(n=36)$, except those of the normal group, were anesthetized with isoflurane, and body temperatures were maintained at $37 \pm 0.5^{\circ} \mathrm{C}$. The abdominal wall was opened, and the uterus was revealed. Thereafter, $0.3 \mathrm{~mL}$ of absolute ethanol was injected with a $1 \mathrm{~mL}$ insulin syringe into one side of uterus. The ethanol was aspirated five minutes later, and the uterus was rinsed with saline three times. The other side of the uterus was treated identically. The abdominal cavity was washed three times before suturing.

2.6.4. Surgical Transfer of UCMSC-AAM. For the AAM/UCMSC-AAM group, transplantation was carried out three estrous cycles after endometrial injury. Rats with normal menstrual cyclicity were anesthetized with isoflurane. A $2 \mathrm{~cm}$ vertical incision was made through the abdominal wall to expose the uteri. Thereafter, a $0.3 \mathrm{~cm}$ vertical incision was made, and the AAM/UCMSC-AAM was transplanted to cover the damaged area with ophthalmic forceps.

2.6.5. Fertility Tests. The uterine function was assessed by the ability to retain embryos for pregnancy. At four cycles after transplantation surgery, rats were mated at $1: 1$ ratio with sexually mature male rats, and the vaginal plugs were checked next morning. Pregnancy outcome data including pregnancy rate, number of neonatal rats, and birth weight were recorded.

2.7. Hematoxylin and Eosin Staining. Hematoxylin and eosin staining were used to assess the morphology of the endometrium. Tissues were embedded in paraffin, sectioned at a thickness of $5 \mu \mathrm{m}$, and stained. Sections were examined under an inverted phase contrast microscope (Leica, German, DMILPH1). Endometrial thickness was measured in cross-section of the uterus as the vertical distance between the endometrial-myometrial interface and the endometrial surface. Image Pro Plus 6.0 software was used to measure endometrial thickness. Five fields in each image were selected for counting. The endometrial gland density was evaluated counted from six randomly selected fields per section under a magnification of $\times 400$. The thickness and the morphology of endometrium were evaluated and compared among the four groups.

2.8. Immunohistochemistry. The expression of keratin, vimentin, and integrin $\beta 3$ was detected by immunohistochemistry. Slides were incubated with a rabbit antivimentin monoclonal antibody, a mouse anti-keratin monoclonal antibody, and a rabbit anti-integrin $\beta 3$ monoclonal antibody, followed by use of the Polink-2 Plus Polymer HRP Detection System for Mouse Primary Antibodies and the Polink-2 Plus Polymer HRP Detection System for Rabbit Primary Antibodies. The color was developed by diaminobenzidine (DAB), and nuclei were stained with hematoxylin.

Immunostaining was evaluated by two independent pathologists blinded to the information. Specimens were scored according to the intensity of the color, which was reflected by a grayscale value within Image Pro Plus 6.0 


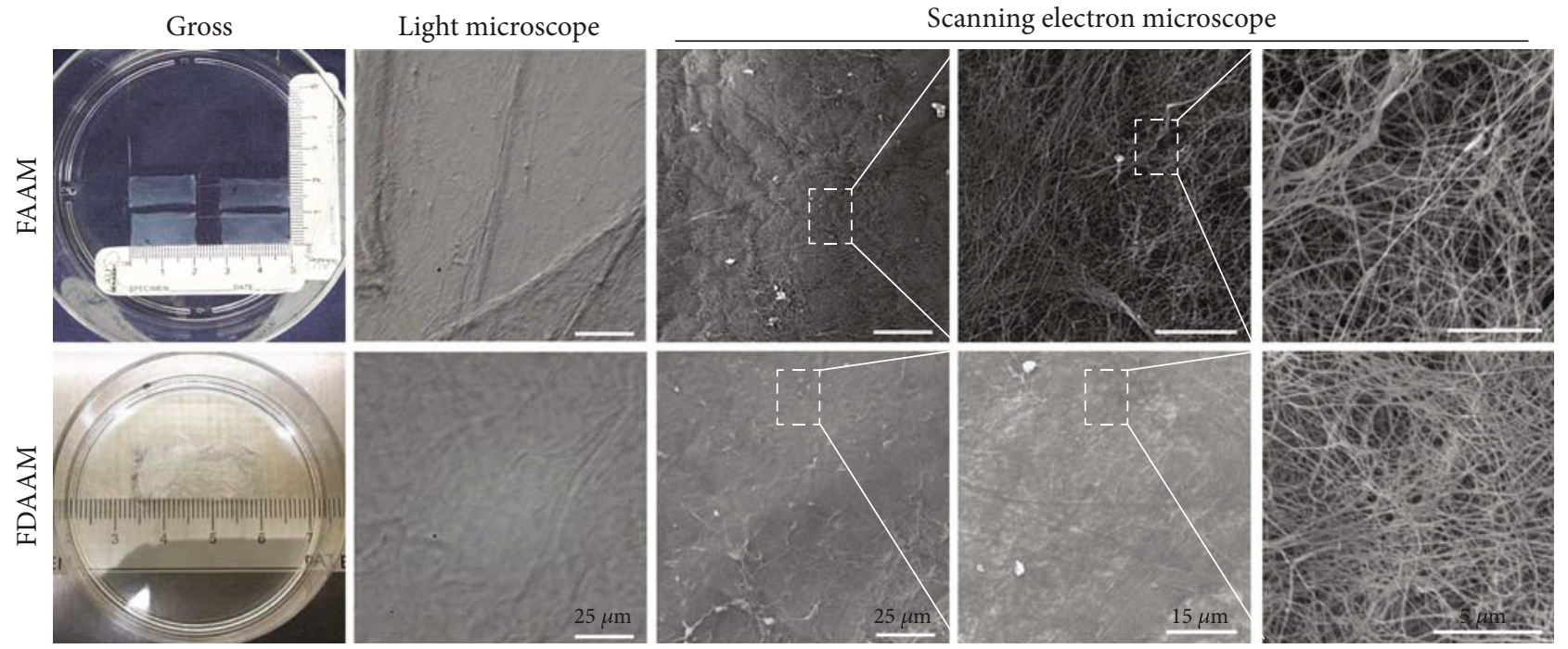

FIGURE 1: Morphology of FAAM and FDAAM. (a) Gross view, under light microscope and scanning electron microscope. Scale bars, $25 \mu \mathrm{m}$, $15 \mu \mathrm{m}$, and $5 \mu \mathrm{m}$. FAAM: fresh acellular amniotic matrix; FDAAM: freeze-dried acellular amniotic matrix.

software. Five fields in each image were selected for counting. Antibodies and dilutions used in immunostaining were showed in Table S1.

\subsection{Quantitative Reverse-Transcription Polymerase Chain} Reaction ( $q R T-P C R)$. The expression of keratin, vimentin, integrin $\beta 3$, IL- $2, \mathrm{TNF} \alpha$, IFN- $\gamma$, IL-4, IL-10, VEGF, MMP9, and $\mathrm{Ki}-67$ was assessed. Total RNA from rat uteri was isolated using TRI Reagent (Sigma) according to the manufacturer's protocol. Complementary DNAs (cDNAs) were synthesized using Trans Script One-Step gDNA Removal and cDNA Synthesis Super Mix (TransGen Biotech, Beijing, China). Real-time quantitative PCR was performed using primers and the Universal KAPA SYBR FAST qPCR Kit (Roche, Switzerland) in a 7900 Real-Time PCR System (Applied Biosystems). Glyceraldehyde 3-phosphate dehydrogenase (GAPDH) was used as a control. All experiments were repeated at least three times. Primer sequences used in realtime quantitative PCR were showed in Table S2.

2.10. Safety Assay. The health of the rats was closely monitored throughout the study. Biochemical tests were performed using the HITACHI LST008 System housed in the Laboratory of Peking University People's Hospital. These tests include an assessment of liver and kidney function and measurements of electrolytes such as AST, ALT, ALP, UA, $\mathrm{UN}, \mathrm{Ca}$, and $\mathrm{P}$. The heart, liver, spleen, lung, and kidney of rats of the injured group, the AAM group, the UCMSCAAM group, and the normal group were stained with $\mathrm{HE}$ and examined for abnormal manifestations such as tumor formation. These blood and organ tissues were acquired three estrus cycles after transplantation surgery.

2.11. Statistical Analysis. Statistical analysis was performed with SPSS 20.0 software (IBM, Armonk, NY, USA). Numerical data were represented as means \pm standard deviation. Normality testing (Shapiro-Wilk) was performed for all experiments. For nonparametric statistics, non-Gaussian dis- tributed data were analyzed using the Mann-Whitney $U$ test and presented as populations with median values indicated by bars. For parametric statistics, data were assumed to be Gaussian distributed and analyzed using unpaired Student's $t$-test. Data was presented as a mean value with 95\% confidence interval (CI). The chi-squared test was used to examine the differences between two or three proportions. $P$ values $<0.05$ were considered to be statistically significant.

\section{Results}

3.1. Human Acellular Amniotic Matrix. Both FAAM and FDAAM were characterized by a semitransparent and tough film. By microscopy, there were no blood vessels, nerves, and lymphatic vessels. Collagen and mesh fibers were interwoven, with the 3D network having an uneven thickness as observed by scanning electron microscopy. There were no cells on the surfaces of both FAAM and FDAAM. The FAAM mesh was relatively loose compared to that of FDAAM preserved at low temperature for half a year after lyophilization. The mesh gap on FAAM was approximately $0.5-15 \mu \mathrm{m}$, whereas that of FDAAM was $0.2-11 \mu \mathrm{m}$ (Figure $1(\mathrm{a})$ ).

3.2. UCMSC-AAM Carrying Capacity. UCMSCs attached to FAAM and FDAAM approximately $30 \mathrm{~min}$ after seeding. By day 5, UCMSCs proliferated to cover both FAAM and FDAAM with long fusiform and polygonal UCMSCs densely distributed on the surface of both matrixes as observed by fluorescent microscopy (Figure 2(a)).

By immunofluorescence staining, UCMSCs were detected on the surfaces of the matrixes before and after lyophilization (Figure 2(b)). By SEM, the morphology of UCMSCs was normal, with cells attaching to the mesh tightly (Figure 2(c)). On day 3, the average UCMSC loading was approximately $0.72 \pm 0.147 \times 10^{7}$ for FAAM and $0.71 \pm$ $0.163 \times 10^{7}$ for FDAAM $(P=0.22)$, and there was no significance between the groups (Figure 2(d), Table 1). 


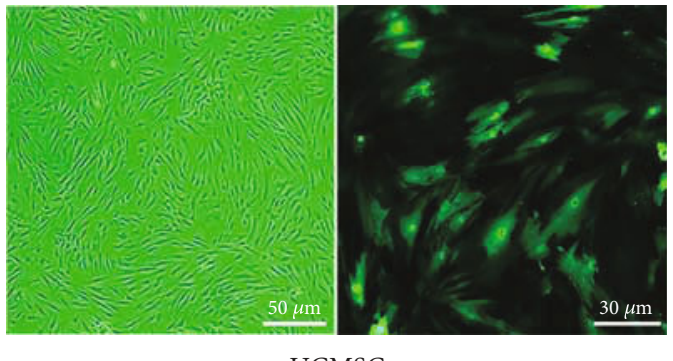

UCMSC

(a)

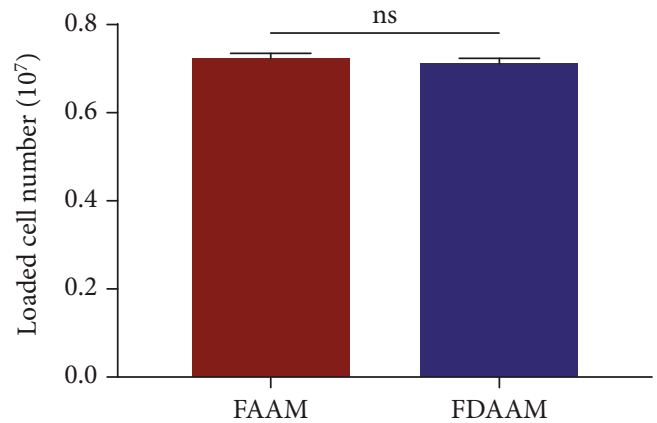

(b)

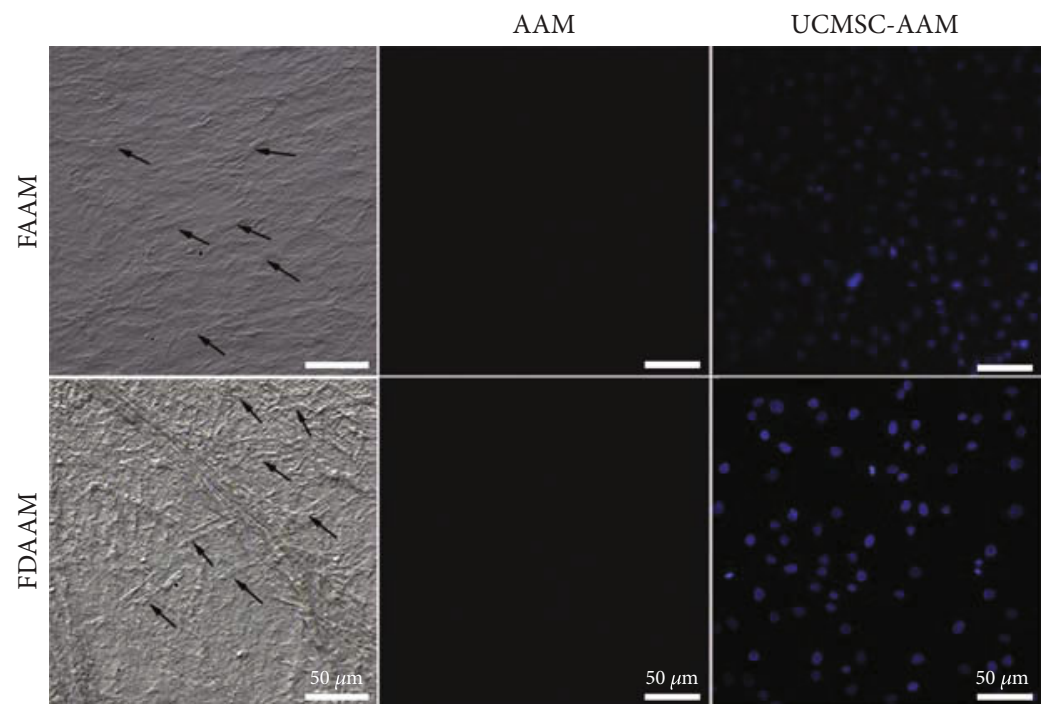

(c)

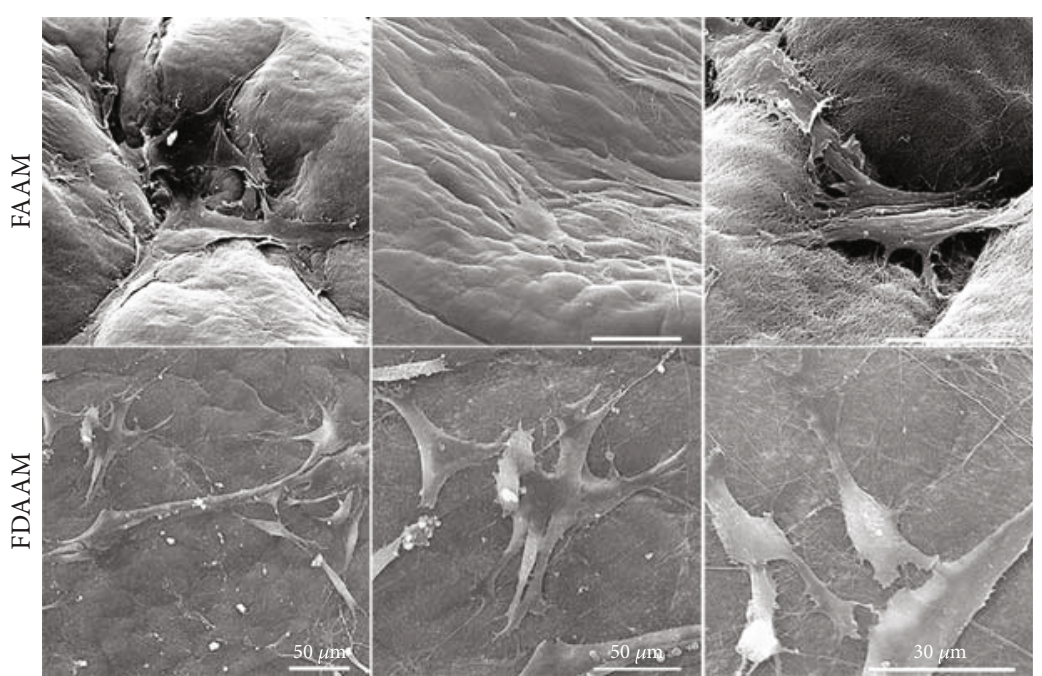

(d)

Figure 2: Establishment of UCMSC-AAM complex. (a) Morphology of human UCMSCs under a light microscope. Scale bars, $50 \mu \mathrm{m}$. UCMSCs were observed by the green fluorescence of green fluorescent protein under a fluorescence microscope. Scale bars, $30 \mu \mathrm{m}$. (b) Statistical analysis of the number of loaded cells on FAAM and FDAAM counted from six randomly selected pieces (ns: $P>0.05$ ). Data were presented as mean \pm standard deviation. (c) UCMSCs were detected on FAAM and FDAAM under light microscope and fluorescence microscope. Scale bars, $50 \mu \mathrm{m}$. Arrowheads indicate seeded UCMSCs. Cell nuclei were stained with DAPI (blue). (d) UCMSC-AAM under scanning electron microscope. Scale bars, $50 \mu \mathrm{m}, 30 \mu \mathrm{m}$. UCMSC: umbilical cord-derived mesenchymal stem cell; FAAM: fresh acellular amniotic matrix; FDAAM: freeze-dried acellular amniotic matrix. 
Table 1: Cell number loaded on the amniotic matrix before and after lyophilization $(\bar{X} \pm S)$.

\begin{tabular}{lcc}
\hline Group & Number of samples & Cell number $\left(10^{7}\right)$ \\
\hline $\begin{array}{l}\text { Fresh amniotic matrix } \\
\text { (FAAM) }\end{array}$ & 6 & $0.72 \pm 0.147$ \\
$\begin{array}{l}\text { Freeze-dried amniotic } \\
\text { matrix (FDAAM) }\end{array}$ & 6 & $0.71 \pm 0.163$ \\
$P$ value & \multicolumn{2}{c}{$P>0.05$} \\
\hline
\end{tabular}

3.3. Assessment of Endometrial Morphology and Thickness. Three estrous cycles later after transplantation, the endometrial morphology and thickness were compared among the four groups.

Endometrial thickness and morphology were significantly different between injury and UCMSC-AAM groups. For the normal endometrium, the epithelial border was intact and continuous, and the surface was smooth and wavy. Glandular epithelial and luminal epithelial cells were intact and tightly arranged, and the morphology of blood vessels and glands was normal. For the injured endometrium, the endometrium was partially interrupted and less continuous, and the luminal epithelial cells (indicated by black arrows) and the glandular epithelial cells (indicated by red arrows) showed vacuolar and a low columnar or flat shape. Glands were scattered and with incomplete edge. For the UCMSCAAM group, the structure of glands was more complete with smooth edge, and the luminal epithelial cells and glandular epithelial cells were more tightly arranged, with intact cell membrane and rich cellular content, closing to normal cells (Figure 3(a)).

The number of endometrial glands was assessed by $H \& E$ staining. There were more endometrial glands per uterine cross-section in the UCMSC-AAM group $(31.67 \pm 6.24)$ compared with the injury group $(16.67 \pm 2.56, P<0.001)$ and the AAM group $(18.50 \pm 3.30, P<0.001)$, but less than the normal group $(41.17 \pm 1.95, P=0.0048)$ (Figure 3(a)).

The endometrial thickness of endometrium in the UCMSC-AAM group $(335.00 \pm 80.07)$ was significantly higher than that of the injury group $(335.00 \pm 80.07, P=$ $0.0004)$ and the AAM group $(367.50 \pm 78.75, P=0.0066)$, but less than the normal group $(687.64 \pm 98.15, P=0.0005)$. The endometrial thickness in the AAM group increased compared to the injury group, but there was no statistically significant difference between the groups $(P=0.86)$ (Figure 3(a), Table 2).

\subsection{Expression of Keratin, Vimentin, and Endometrial} Receptivity-Related Marker Integrin $\beta 3$. In the endometrial tissue, keratin mainly expressed in the cytoplasm of glandular epithelial or luminal epithelial cells, and vimentin expressed in the cytoplasm of stromal cells, while integrin $\beta 3$ mainly expressed in the luminal and glandular epithelial cells during the implantation window. Under a light microscope, keratin and vimentin appear as brown particles in the cell cytoplasm, while integrin $\beta 3$ shows brown granular particles in the cell cytoplasm and cell membrane. The positive and negative controls were showed in Figure S2.
The protein expression of keratin and integrin $\beta 3$ in the UCMSC-AAM group was significantly higher than that in the injury group. The IOD values of keratin and integrin $\beta 3$ in the UCMSC-AAM group were significantly higher than those in the injury group ( $P \leq 0.001, P \leq 0.01$, respectively). It is worth noting that the IOD value of keratin in the UCMSC-AAM group was significantly higher than the AAM group $(P \leq 0.05)$. The IOD value of vimentin in the UCMSC-AAM group was higher than the injury group, but there was no significant difference $(P>0.05)$ (Figure $3(b)$, Table 3).

The mRNA expression of keratin in the UCMSC-AAM group increased compared with injury $(P \leq 0.0001)$ and AAM groups $(P \leq 0.001)$. The mRNA expression of vimentin in the UCMSC-AAM group was higher than the injury group $(P \leq 0.001)$ and the AAM group $(P \leq 0.001)$. The mRNA expression of integrin $\beta 3$ in the UCMSC-AAM group was increased compared with the injury group $(P \leq 0.05)$, and there was no significant difference between the AAM group and UCMSC-AAM group $(P>0.05)$ (Figure $3(\mathrm{c})$ ).

3.5. $m R N A$ Expression of VEGF, MMP9, and Ki-67. VEGF (vascular endothelial growth factor) was reported to promote the increase of vascular permeability, degeneration of extracellular matrix, vascular endothelial cell migration, proliferation, and angiogenesis [32]. Matrix metalloproteinase 9 (MMP9) is a matrix metalloproteinase associated with extracellular matrix degradation. Cell proliferation-associated nuclear antigen $\mathrm{Ki}-67$ indicates that cell proliferation was induced.

The mRNA expression of MMP9 in the UCMSC-AAM group increased compared with injury $(P \leq 0.0001)$ and AAM groups $(P \leq 0.0001)$, whereas the expression of MMP9 in the AAM group was increased compared with the injury group $(P \leq 0.0001)$. Similarly to MMP9, the expression of $\mathrm{Ki}-67$ in the UCMSC-AAM group was higher than the injury group $(P \leq 0.05)$ and the AAM group $(P \leq 0.001)$. By contrast, the mRNA expression of VEGF in the UCMSC-AAM group was decreased compared with the injury group $(P \leq 0.0001)$ and $\mathrm{AAM}$ group $(P \leq 0.0001)$ (Figure 3(d)).

3.6. UCMSC-AAM Regulates the Expression of Inflammatory Factors In Vivo. The damage, repair, and regeneration of the endometrium are accompanied by inflammation. The mRNA expression of proinflammatory factors (IL-2, TNF $\alpha$, and IFN- $\gamma$ ) in the UCMSC-AAM group was significantly decreased compared with the injury group $(P \leq 0.0001$ $/ P \leq 0.0001 / P \leq 0.0001)$, whereas the expression of antiinflammatory factors (IL-4 and IL-10) was increased $(P \leq 0.0001 / P \leq 0.0001 / P \leq 0.0001)$ (Figure $3(\mathrm{~d}))$.

3.7. Fertility Tests. At 4 estrus cycles after transplantation surgery, rats were mated at $1: 1$ ratio with sexually mature male rats. In the injury group, AAM group, and the UCMSCAAM group, no rats got pregnant. In the normal group, the average fetal number was $5.5 \pm 0.23$ per side of uterus $(6,7$, $6,5,6,5,6,6,5,5,5,4)$. 

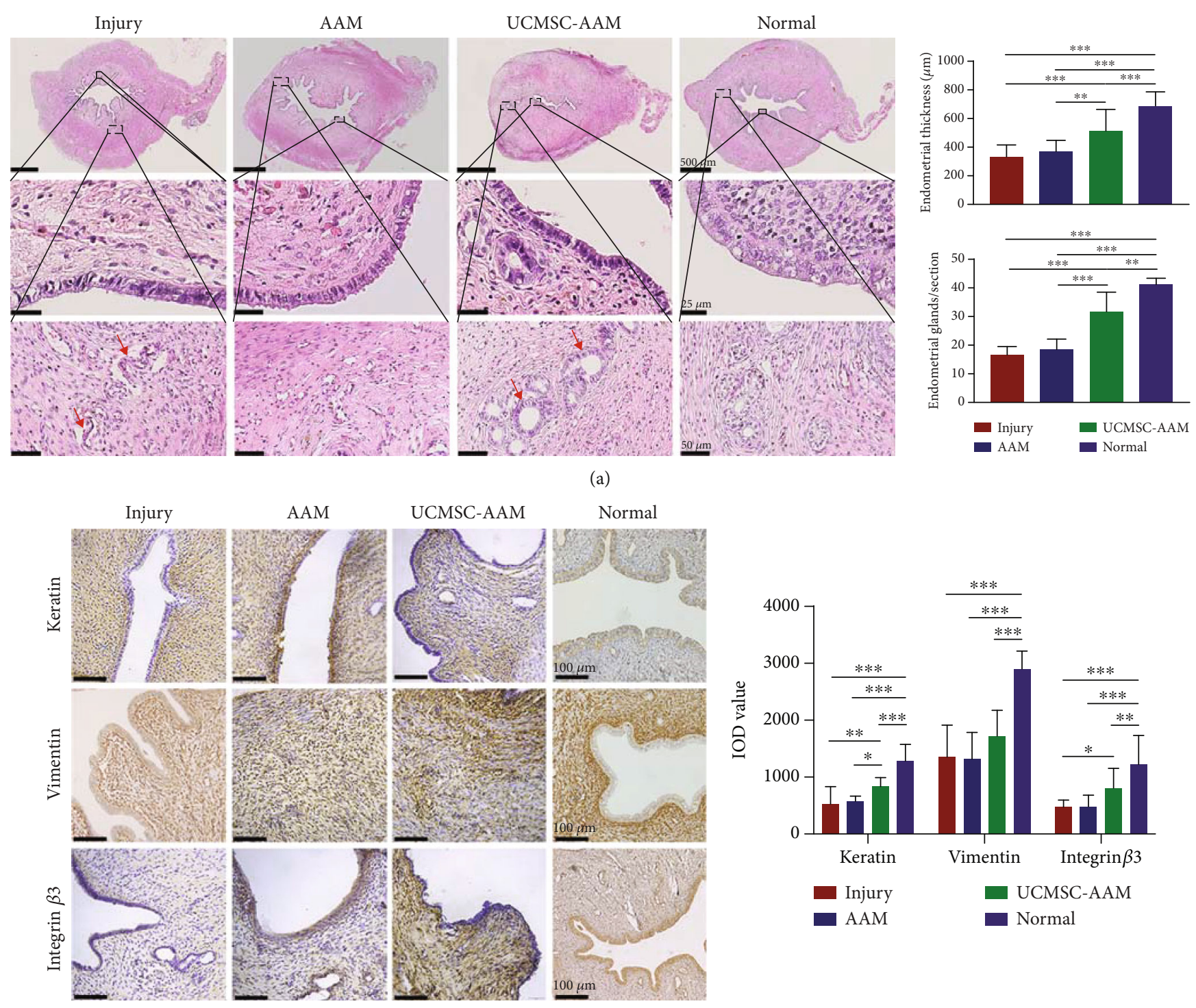

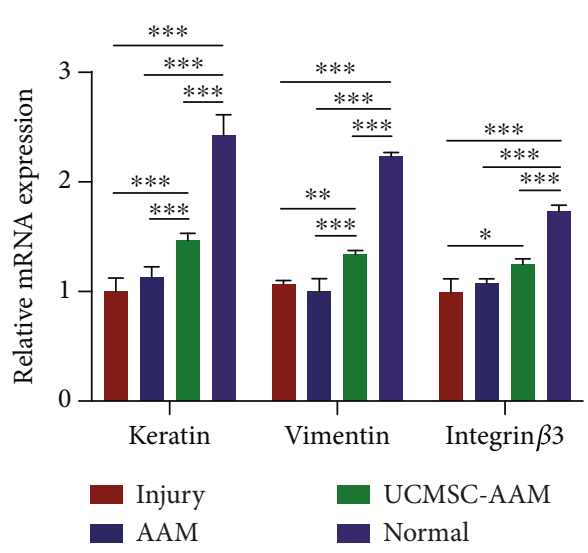

(c)

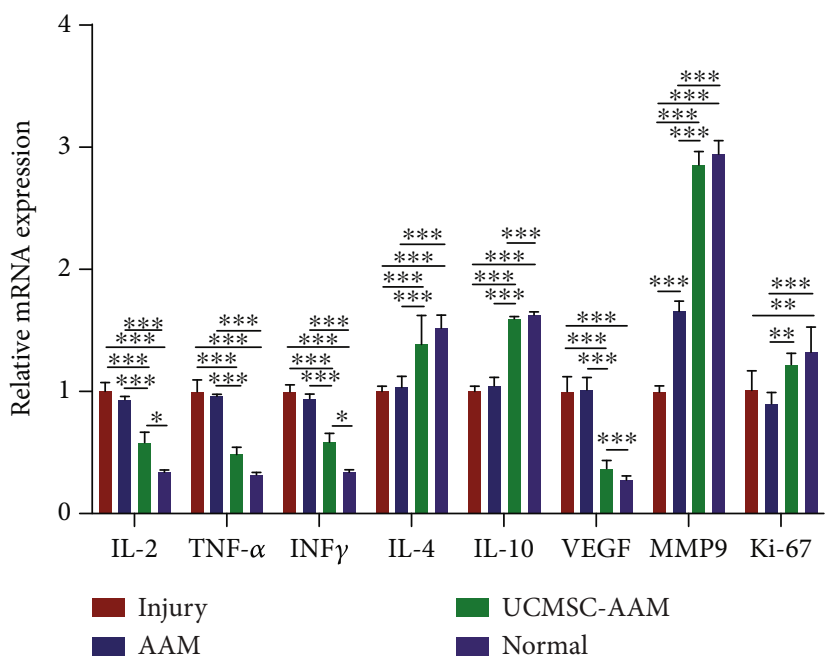

(d)

Figure 3: Continued. 

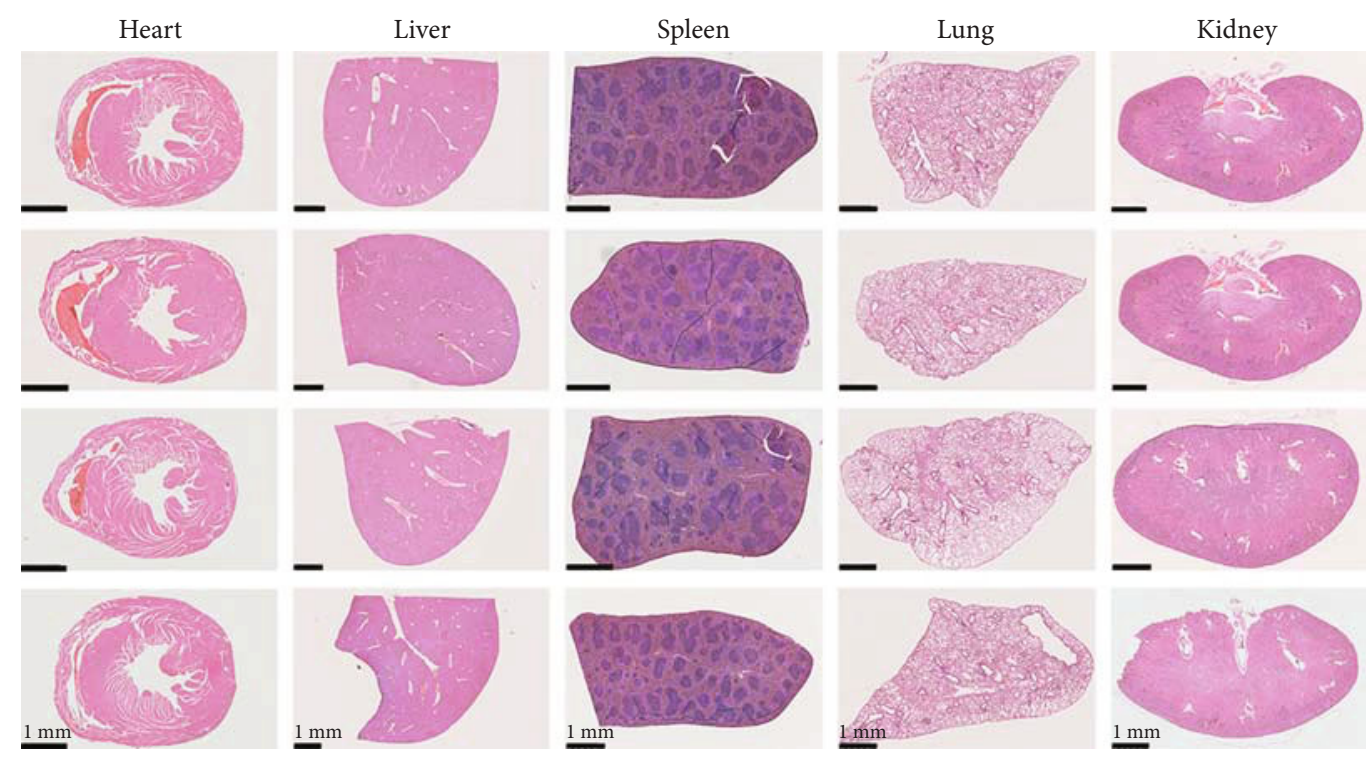

(e)

FIGURE 3: UCMSC-AAM transplantation promotes endometrial thickness, mRNA and protein expression, and regulates inflammation factors of injured endometrium. (a) Hematoxylin and eosin (H\&E) staining of uterine in the injury group, the AAM group, the UCMSCAAM group, and the normal group. Scale bars, $500 \mu \mathrm{m}, 25 \mu \mathrm{m}$, and $50 \mu \mathrm{m}$. The black arrows indicate epithelial cells, and the red arrows indicate glands. Each experiment was repeated four times. Statistical analysis of the endometrial thickness measured by Image-Pro Plus 6.0 software. ${ }^{*} P<0.05,{ }^{*} P<0.01,{ }^{* * *} P<0.001$. (b) Immunohistochemical staining of keratin, vimentin, and integrin $\beta 3$ for epithelial cells, stromal cells, and endometrial receptivity in endometrium of the injury group, the AAM group, the UCMSC-AAM group, and the normal group. Scale bars, $100 \mu \mathrm{m}$. Statistical analysis of IOD (Integral optical density) value of positive areas measured by Image-Pro Plus 6.0 software. ${ }^{*} P<0.05,{ }^{* *} P<0.01,{ }^{* * *} P<0.001$. (c) Relative mRNA expressions of keratin, vimentin, and integrin $\beta 3$ in endometrium tissues of rats in the injury group, the AAM group, the UCMSC-AAM group, and the normal group that were compared. The relative expression is the average of $2^{-\Delta \Delta \mathrm{Ct}} \pm \mathrm{SEM} .{ }^{*} P<0.05,{ }^{* *} P<0.01$, ${ }^{* * *} P<0.001$. (d) Relative mRNA expressions of IL-2, TNF $\alpha$, IFN- $\gamma$, IL-4, IL-10, VEGF, MMP9, and ki67 mRNA in endometrium tissues of rats in the injury group, the AAM group, the UCMSC-AAM group, and the normal group that were compared. The relative expression is the average of $2^{-\Delta \Delta \mathrm{Ct}} \pm \mathrm{SEM} .{ }^{*} P<0.05,{ }^{* *} P<0.01,{ }^{* * *} P<0.001$. (e) $\mathrm{HE}$ staining of heart, liver, spleen, lung, and kidney in the injury group, the AAM group, the UCMSC-AAM group, and the normal group.

TABLE 2: Endometrial thickness in the groups $(\bar{X} \pm S)$.

\begin{tabular}{lccc}
\hline Group & Number of samples & Thickness $(\mu \mathrm{m})$ & $P$ value \\
\hline Injury & 12 & $335.00 \pm 80.07$ & - \\
AAM & 12 & $367.50 \pm 78.75$ & $P=0.86$ \\
UCMSC- & 12 & $513.33 \pm 148.59$ & $P=0.0004$ \\
AAM & 12 & $687.64 \pm 98.15$ & $P<0.001$ \\
Normal &
\end{tabular}

$P$ value: groups compared with the injury group.

3.8. Safety of the UCMSC-AAM Transplantation In Vivo. As showed in Figure 3(e), the morphology of the heart, liver, spleen, lung, and kidney was normal, and there was no malignant tumor formation. Biochemical tests revealed no significant differences in any parameter between the UCMSCAAM group and the normal group $(P>0.05)$ (Table 4$)$.

\section{Discussion}

For IVF patients, a damaged endometrium is one of the reasons of repeated implantation failure, as the endometrium must be thick enough for successful embryo implantation [33]. Invasive intrauterine surgery is the most common cause of a thin endometrium and IUA formation. The basal layer is damaged, which is accompanied by the severe loss of resident stem cells and the destruction of the microenvironment $[34,35]$.

A variety of methods have been used to treat endometrial injury with little success. MSCs are major histocompatibility complex (MHC) class II negative and express both an immunoprivileged and immunomodulatory phenotype [36], making them a potential cell source for cell replacement therapies. The most studied among them are bone marrow stem cells (BMSCs), and UCMSCs showed a greater proliferative capacity and with no contact inhibited cell growth phenomenon when compared with BMSCs. Additionally, UCMSCs share common Wnt signaling pathways and exhibited the equal capacity to transduce canonical Wnt signaling in response to Wnt3a, a canonical Wnt with BMSCs [37]. There is no previous basic research reported that MSC xenotransplantation causes immune rejection. In a report of UCMSC subarachnoid transplantation for the treatment of spinal cord injury, $14.1 \%$ of patients had transient low fever and $1 \%$ suffered from dizziness, which were considered a stress response and disappeared after observation or conservative treatment, and no evidence-based reasons demonstrated that the mild adverse events are related to allogeneic rejection caused by MSC transplantation [38]. UCMSCs have been reported successfully used in several cases of tissue 
TABLE 3: IOD value of endometrial cell-specific proteins and endometrial receptivity protein in the groups $(\bar{X} \pm S)$.

\begin{tabular}{lccr}
\hline Group & Keratin & Vimentin & Integrin $\beta 3$ \\
\hline Injury & $535.02 \pm 325.89$ & $1363.33 \pm 598.59$ & $481.25 \pm 131.39$ \\
AAM & $580.75 \pm 99.09$ & $1325.50 \pm 502.93$ & $492.92 \pm 212.88$ \\
UCMSC-AAM & $841.67 \pm 165.87$ & $1728.58 \pm 484.90$ & $815.58 \pm 373.83$ \\
Normal & $1288.07 \pm 290.45$ & $2902.36 \pm 313.99$ & $1229.79 \pm 504.23$ \\
\hline
\end{tabular}

TABLE 4: Blood chemistry results three estrus cycles after UCMSCAAM transfer.

\begin{tabular}{lccc}
\hline & Normal & AAM-MSC & $P$ value \\
\hline AST $(\mathrm{U} / \mathrm{L})$ & 128.1 & 117.8 & $P>0.05$ \\
ALT $(\mathrm{U} / \mathrm{L})$ & 47.1 & 50.6 & $P>0.05$ \\
ALP $(\mathrm{U} / \mathrm{L})$ & 138.8 & 130.7 & $P>0.05$ \\
GGT $(\mathrm{U} / \mathrm{L})$ & 1.4 & 0.9 & $P>0.05$ \\
TP $(\mathrm{g} / \mathrm{L})$ & 53.05 & 60.45 & $P>0.05$ \\
ALB $(\mathrm{g} / \mathrm{L})$ & 36.7 & 40.4 & $P>0.05$ \\
A/G & 2 & 2 & - \\
UN $(\mu \mathrm{mol} / \mathrm{L})$ & 7.46 & 7.24 & $P>0.05$ \\
CRE $(\mu \mathrm{mol} / \mathrm{L})$ & 57 & 48 & $P>0.05$ \\
UA $(\mu \mathrm{mol} / \mathrm{L})$ & 145.6 & 131.1 & $P>0.05$ \\
LDH $(\mathrm{U} / \mathrm{L})$ & 525 & 496 & $P>0.05$ \\
CK $(\mathrm{U} / \mathrm{L})$ & 696.3 & 712.9 & $P>0.05$ \\
Ca $(\mathrm{mmol} / \mathrm{L})$ & 2.585 & 2.542 & $P>0.05$ \\
P $(\mathrm{mmol} / \mathrm{L})$ & 2.921 & 2.781 & $P>0.05$ \\
Glu $(\mathrm{mmol} / \mathrm{L})$ & 7.64 & 8.74 & $P>0.05$ \\
CHO $(\mathrm{mmol} / \mathrm{L})$ & 1.774 & 1.523 & $P>0.05$ \\
\hline AAM & & &
\end{tabular}

AAM: acellular amniotic matrix; $P$ value: UCMSC-AAM group compared with the normal group.

injury and inflammation [39-42]. Dai et al. transplanted UCMSCs previously seeded on synthetic collagen scaffolds into rats and observed that the labeled UCMSCs mainly distributed in the stromal layer of the damaged uterus. In addition, the number of labeled UCMSCs in the treated group was significantly higher than that in the untreated group [43]. In another study, Hu et al. transplanted artificial collagen scaffolds loaded with UCMSCs into the uteri of infertile patients with IUA formation. By 30 months, 10 out of 26 patients achieved pregnancy, with eight delivering healthy babies, one undergoing an early spontaneous abortion and one undergoing a late abortion [41]. A previous study reported that the immigration of UCMSCs into damaged tissue can be induced by the microenvironment [44]. UCMSCs can also secrete numerous cell growth factors to regulate cell differentiation and to repair damaged tissues. By contrast, UCMSCs have also been reported to inhibit the proliferation and the activation of immune cells through direct contact and secretion of regulatory factors, thereby suppressing the immune response and reducing the inflammatory damage $[40,45,46]$.

An appropriate transplantation route should be selected for MSCs. Studies on the transplantation of BMMSCs and
UCMSCs for spinal cord injury, myocardial ischemia, liver failure, and diabetes all showed significant differences in various aspects of cell behavior such as cell migration [41, 47, 48]. As a result, the degrees of tissue repair and functional recovery are different, which may be related to cell number, survival time, cell activity, and the microenvironment [21, 49]. Previous studies have reported that MSCs can be transplanted by intrauterine infusion, as well as by intravenous injection and direct intrauterine transplantation [42, 44, 49, 50]. From the perspective of clinical application, because of the contraction of uterus, intrauterine infusion leads to cells easily flowing out of the uterine cavity. Considering the needs of gestating a fetus, the safety of intravenous injection is controversial. Direct intrauterine transplantation of MSC-carrying graft can form a local environment with high concentration of cells, no additional migration time required, which is conducive to give full play to cells' functions. Commonly used cell scaffold materials include animal-derived type I collagen, alginate extracted from seaweed, chitosan extracted from crab shells, synthetic organic polymer materials, and inorganic materials such as calcium phosphate cement and hydroxyapatite. These cell carrier and materials have disadvantages such as high economically consuming, insufficient local stem cell concentrations, uneven distribution, easy outflow from the uterine cavity, contamination by animal-origin components, and potential toxic effects. Also, patients with endometrial injury are always accompanied by intrauterine adhesions. It is important to select a material that can serve as cell carrier as well as prevent readhesions.

AM was proved effective on the recovery of menstruation, prevention of re-adhesion, and improvement of endometrial thickness in patients with injured endometrium [28, 51].AM contains a variety of growth factors, which are conducive to the differentiation and proliferation of epithelial cells. Inflammatory factors can inhibit stromal cell proliferation and neovascularization induced by cytokines, thereby suppressing inflammation, preventing new blood vessel and scar formation to reduce adhesion recurrence, and promote tissue repair and healing. AAM is the biofilm containing the basal layer and dense layer of AM; comparing with other synthetic materials, AAM is easily acquired and economically feasible, also with no toxicity, no blood vessels, and no HLA antigens. The basal layer contains I, III, IV, V, and VIII type collagens, fibronectin, laminin, and proteoglycan. The dense layer is made up of mesh fibers, and it can prevent inflammatory cells from infiltrating the lesion. The fibers provide a scaffold for cell growth and migration, and they can enhance the attachment when UCMSCs were seeded $[29,52]$. What is more, AAM can effectively attach to lesions so UCMSCs 
proliferate and spread uniformly on the endometrial surface. AAM completely degrades 4 months after transplantation under chicken skin [25]. However, there is no report on the degradation time of AAM in the uterus.

Considering the safety of AAM, and to exclude the window period infection, FDAAM was prepared and stored at $-20^{\circ} \mathrm{C}$ for at least 1 year after lyophilization. The donors' second blood detection was performed 3 months after the specimen was acquired, and the results were negative. FDAAM maintained normal fibrous network structure and secretion of growth factors, cytokines, and other substances. Russo et al. analyzed the levels of EGF, HGF, KGF, FGF, and TGF- $\beta$ in fresh and freeze-dried amniotic membranes, and the levels in freeze-dried amniotic membranes were $94.43 \%$ $\pm 8.83,63.78 \% \pm 1.27,78.55 \% \pm 3.98,71.64 \% \pm 1.62$, and $58.77 \% \pm 5.07$ those of fresh amniotic membranes. The levels of PDGF-AA, PDGF-BB, TIMP-1, TIMP-2, FGF2, and IL-10 were almost similar between the two types of amniotic membranes [53-55]. Decellularization of AM removed epithelial cells and avoided the possibility of immune rejection. Lyophilization can mostly preserve the active substances contained in the source materials and provides opportunities for secondary screening of infectious diseases to ensure the safety, making FDAAM a promising cell carrier and bioactive material for promotion and application. FDAAM loaded with various therapeutic cells, such as UCMSCs, combining advantages of both, has great potential in cell replacement therapy and regenerative medicine fields. At the present study, AAM served as a scaffold that maintains the cell growth and viability, as well as a biological material to separate the adhered endometrium, resulting in wound repair and IUA recurrence decline.

Our results demonstrated that UCMSCs attached to AAM and subsequently proliferated. UCMSCs showed a normal fusiform or polygonal shape, the number of cells loaded on FDAAM was identical to that of FAAM, and both matrixes have similar characteristics. In this study, no inflammatory response, infection, malignant tumors, and blood biochemical abnormalities were observed in rats receiving AAM/UCMSCAAM transplantation.

After transplantation of UCMSC-AAM, the thickness of injured endometrium increased significantly, with morphology improvements. The mRNA and protein expression of keratin and integrin $\beta 3$ significantly increased, reflecting the growth of endometrial epithelial cells and promotion of endometrial receptivity. The vimentin expression can reflect the growth of endometrial stromal cells, and the mRNA expression of vimentin was significantly increased; although, the IOD value was not significant on protein level. In fact, from DNA to mRNA to the protein expression, there are many factors involved in three levels of regulation including transcription, translation, and posttranslation. It cannot be ruled out that the negative regulatory factors that control the translation of vimentin are activated. Antibody specificity may also be one of the influencing factors. The expression of Ki-67 increased, indicating regeneration of the injured endometrium.

Endometrial injury is always accompanied by IUA in patients, the essence of which is fibrosis [56]. Vascular defects can lead to hypoxia, which is a potent stimulator of the VEGF expression. VEGF actions include not only mitogenic activation of endothelial cells but also increased endothelial chemotaxis, and induction of serine proteases (uPA, tPA) and collagenases triggers angiogenesis and cytoplasmic calcium accumulation, leading to endometrial fibrosis and collagen deposition. It also has a high affinity for fibrinogen and fibrin monomer, and the deposition of fibrin monomer can induce the aggregation of fibroblasts, which ultimately results in increased synthesis of the extracellular matrix (ECM). Moreover, Chaudhary and his group demonstrated that inhibition of the signaling pathways modulated by VEGF significantly attenuated fibrosis-associated diseases [57].

In consistence with the previous studies [58, 59], our results demonstrated that the mRNA expression of VEGF in endometrium in the UCMSC-AAM group decreased compared with the injury group and AAM group, higher than that of the normal group, indicating the mitigation of fibrosis after transplantation of UCMSC-AAM. It is reported that the expression of VEGF can be regulated by various growth factors and cytokines (EGF, TGF $\beta$, PGE2, IL-1, IL-6) [60].

Studies have reported the increase of VEGF after G-CSF perfusion and MSC transplantation, which is contrary to our results. Considering the treatment methods differ, diverse pathways are activated resulting in the different expression trends. It was reported that the recovery of injured endometrium includes three stages, the early repair stage, scar stage, and postrepair stage, and the hardness of the repair layer changes from soft to hard and then from hard to soft [61]. So, the start time to treat the injured endometrium and the time of sampling after the treatment affect the restore effect and detection results. In addition, the time point of gene and protein change is not synchronized, which can explain the inconsistent results in the VEGF expression. Still, further experiments are needed.

MMP9 is an antifibrotic factor due to its ability to degrade and remodel the ECM. It can affect ECM components, such as gelatin, elastin, and types IV and V collagen and degrade the formed fibrous tissue $[62,63]$. For the UCMSC-AAM group, efficient collagen degradation in uterine scars was observed, consistent with a previous study [64]. The MMP9 expression also significantly increased in the AAM group compared with the injury group, indicating that AAM can facilitate the degradation of fibrous connective tissue and reduce fibrosis [65].

Embryo implantation is a complex process of crosstalk between various signaling molecules at the mother-fetal interface. A gradient of chemokines and cytokines is produced by endometrial cells to guide the blastocyst to the implantation site. Studies revealed that proinflammatory cytokines, such as IL-6, leukemia inhibitory factor, IL-8, and $\mathrm{TNF} \alpha$, participate in endometrial remodeling and immune cell recruitment into the decidua [66]. Similarly, increased IL-4 secretion from peripheral blood mononuclear cells 4 weeks after embryo transfer was reported [67]. Abnormal inflammation respond affects embryo implantation and pregnancy maintenance. After damage of the endometrium and transplantation of UCMSC-AAM, numerous proinflammatory and anti-inflammatory cytokines were produced at 
the injured site. The expression of proinflammatory factors, such as IFN- $\gamma, \mathrm{TNF} \alpha$, and IL-2, in the injury group was higher than that in the UCMSC-AAM group. Compared with the injury group, the IL-4 and IL-10 expression was noticeably enhanced in the uterus of the UCMSC-AAM group, indicating that AAM can regulate inflammation and reduce inflammation together with UCMSCs in vivo.

Still, there are limitations in the present study. There are no offspring obtained in the AAM and UCMSC-AAM group, which may relate to the time duration from transplantation to mating. Different mating time should be set to explore the appropriate repair time for endometrium, which will be carried out in our subsequent research. The badly damaged endometrium may also lead to the failure implantation of embryos, which should be modified. Also, multiple operations and possible damage of ovary are negative factors for conception and pregnancy to rats.

There is no report on the transplantation of UCMSCs using AAM as the cell carrier to treat endometrial injury, which remains a challenge in assisted reproductive technology. The good biocompatibility, toughness, and ability to regulate inflammation make AAM a promising cell carrier. Moreover, the successful preparation of FDAAM and the construction of UCMSC-FDAAM are of great significance for future clinical applications. The present report is the first study to explore the safety and effects of AAM as a cell carrier in the transplantation of UCMSCs to repair endometrial damage on a rat model.

\section{Conclusion}

Transplanted UCMSC-AAM can promote the proliferation of endometrial epithelial and stromal cells. FDAAM made it possible to assess its safety and production for future clinical applications. Thus, the UCMSC-AAM complex is beneficial in the treatment of women with endometrial injury, and AAM may be promising as a cell carrier.
Abbreviations
AM: $\quad$ Amniotic membrane
AAM: Acellular amniotic membrane
FAAM: $\quad$ Fresh acellular amniotic membrane
FDAAM: Freeze-dried acellular amniotic membrane
UCMSC: Umbilical cord mesenchymal stem cell
IUA: Intrauterine adhesions
IUDs: Intrauterine devices
G-CSF: Granulocyte colony stimulating factor
MMP9: $\quad$ Matrix metallopeptidase 9
BMSCs: Bone marrow mesenchymal stem cells
MSC: $\quad$ Marrow mesenchymal stem cell
PDGF-AA: Platelet-derived growth factor AA
TGF $\beta 1$ : Transforming growth factor $\beta$
VEGF: Vascular endothelial growth factor
FGF2: $\quad$ Fibroblast growth factor 2
CI: $\quad$ Confidence interval
AST: Aspartate aminotransferase
ALT: $\quad$ Alanine aminotransferase
ALP: $\quad$ Alkaline phosphatase
UN: Urea nitrogen
IOD: Integrated optical density
SEM: Scanning electron microscope
EGF: $\quad$ Epidermal growth factor
PGE2: $\quad$ Prostaglandin E2
IFN- $\gamma$ : Interferon- $\gamma$
TNF $\alpha$ : Transforming growth factor- $\alpha$
ECM: $\quad$ Extracellular matrix
TIMP-1: Metallopeptidase inhibitor 1
TIMP-2: $\quad$ Metallopeptidase inhibitor 2.

\section{Data Availability}

All data and figures used to support the findings of this study are included within the article.

\section{Ethical Approval}

Written informed consent was obtained from all donors, and all animal experiments were approved by the Institutional Animal Care and Use Committee of Peking University People's Hospital (Beijing, China): NIH guidelines (or for nonU.S. residents, which were similar to national regulations) for the care and use of laboratory animals (NIH Publication \#85-23 Rev. 1985) were observed.

\section{Consent}

Informed consent was obtained from all participants included in this study. All donors provided written informed consent for the use of amnion membrane.

\section{Conflicts of Interest}

The authors declare no conflict of interests.

\section{Authors' Contributions}

Wang Shan performed experiments, statistical analysis, and prepared the manuscript. Shi Cheng and Shen Huan conceived and designed the study. Cai Xiaohui helped in statistical analysis and animal operation. Wang Yanbin and Chen $\mathrm{Xi}$ conducted experimental technical guidance. Han Hongjing reviewed the manuscript. Wang Shan and Shi Cheng contributed equally to this work.

\section{Acknowledgments}

We thank Chenxi Cao at Peking University Institute of Sports Medicine for technical guidance and Qi Zhou, Liu Wang, Jun Wu, and Gang Chen at the Institute of Zoology, Chinese Academy of Sciences for providing UCMSCs and technical guidance. Our research was supported by the Capital Health Development Scientific Research Project (2018-24085), the Capital Characteristics Clinical Application Research Project (Z161100000516044), and Project of the Scientific Research Development Fund of Peking University People's Hospital (RDH2017-04). 


\section{Supplementary Materials}

Supplementary 1. Figure S1: UCMSCs have stable karyotype, express specific surface antigens, and possess multilineage differentiation potential. (a) UCMSCs maintain normal karyotype after multiple passages. (b) Flow cytometry analysis of specific surface markers in human UCMSCs. (c) Differentiation assays of human UCMSCs. Osteogenesis differentiation was confirmed by immunofluorescence staining with anti-Osteocalcin antibody. Scale bars, $50 \mu \mathrm{m}$. Adipogenesis differentiation was confirmed by immunofluorescence staining with anti- FABP-4. Scale bars, $50 \mu \mathrm{m}$. Chondrogenesis differentiation was confirmed by immunofluorescence staining with anti-Aggrecan antibody. Scale bars, $20 \mu \mathrm{m}$. UCMSC: umbilical cord-derived mesenchymal stem cell. Figure S2: positive and negative controls for keratin, vimentin, and integrin $\beta 3$ staining. (a) Negative and positive control for keratin in thymus of SD rat (Scale bars, $50 \mu \mathrm{m})$, vimentin in testis of SD rat (Scale bars, $250 \mu \mathrm{m})$. and integrin $\beta 3$ in ovary of C57BL/6 N mouse (Scale bars, $50 \mu \mathrm{m}$ ).

Supplementary 2. Table S1: antibodies and dilutions. Table S2: primer sequences used in real-time quantitative PCR.

\section{References}

[1] E. Zupi, G. Centini, and L. Lazzeri, "Asherman syndrome: an unsolved clinical definition and management," Fertility and Sterility, vol. 104, no. 6, pp. 1380-1381, 2015.

[2] M. Khatun, A. Sorjamaa, M. Kangasniemi et al., "Niche matters: the comparison between bone marrow stem cells and endometrial stem cells and stromal fibroblasts reveal distinct migration and cytokine profiles in response to inflammatory stimulus," PLoS One, vol. 12, no. 4, article e0175986, 2017.

[3] H. Campo, A. Murphy, S. Yildiz, T. Woodruff, I. Cervelló, and J. J. Kim, "Microphysiological modeling of the human endometrium," Tissue Engineering. Part A, vol. 26, no. 13-14, pp. 759-768, 2020.

[4] E. J. Guo, J. P. W. Chung, L. C. Y. Poon, and T. C. Li, "Reproductive outcomes after surgical treatment of asherman syndrome: a systematic review," Best Practice \& Research. Clinical Obstetrics \& Gynaecology, vol. 59, pp. 98-114, 2019.

[5] Z. Kalem, M. Namli Kalem, B. Bakirarar, E. Kent, A. Makrigiannakis, and T. Gurgan, "Intrauterine G-CSF administration in recurrent implantation failure (RIF): an Rct," Scientific Reports, vol. 10, no. 1, p. 5139, 2020.

[6] E. G. Pabuçcu, E. Kovanci, Ö. Şahin, E. Arslanoğlu, Y. Yıldız, and R. Pabuçcu, "New Crosslinked Hyaluronan Gel, Intrauterine Device, or Both for the Prevention of Intrauterine Adhesions," JSLS: Journal of the Society of Laparoendoscopic Surgeons, vol. 23, no. 1, 2019.

[7] Y. Y. Kim, K. H. Park, Y. J. Kim et al., "Synergistic regenerative effects of functionalized endometrial stromal cells with hyaluronic acid hydrogel in a murine model of uterine damage," Acta Biomaterialia, vol. 89, pp. 139-151, 2019.

[8] R. Azizi, L. Aghebati-Maleki, M. Nouri, F. Marofi, S. Negargar, and M. Yousefi, "Stem cell therapy in Asherman syndrome and thin endometrium: stem cell- based therapy," Biomedicine \& Pharmacotherapy, vol. 102, pp. 333-343, 2018.
[9] C. E. Gargett and L. Ye, "Endometrial reconstruction from stem cells," Fertility and Sterility, vol. 98, no. 1, pp. 11-20, 2012.

[10] D. Ulrich, K. S. Tan, J. Deane et al., "Mesenchymal stem/stromal cells in post-menopausal endometrium," Human Reproduction, vol. 29, no. 9, pp. 1895-1905, 2014.

[11] Y. Liu, R. Niu, W. Li et al., "Therapeutic potential of menstrual blood-derived endometrial stem cells in cardiac diseases," Cellular and Molecular Life Sciences, vol. 76, no. 9, pp. 1681-1695, 2019.

[12] Y. Cheng, L. Li, D. Wang et al., "Characteristics of human endometrium-derived mesenchymal stem cells and their tropism to endometriosis," Stem Cells International, vol. 2017, Article ID 4794827, 9 pages, 2017.

[13] G. Bodek, J. Bukowska, J. Wisniewska, and A. J. Ziecik, "Evidence for the presence of stem/progenitor cells in porcine endometrium," Molecular Reproduction and Development, vol. 82, no. 3, pp. 182-190, 2015.

[14] F. Alawadhi, H. du, H. Cakmak, and H. S. Taylor, "Bone marrow-derived stem cell (BMDSC) transplantation improves fertility in a murine model of Asherman's syndrome," PLoS One, vol. 9, no. 5, article e96662, 2014.

[15] I. Cervelló, C. Gil-Sanchis, A. Mas et al., "Bone marrowderived cells from male donors do not contribute to the endometrial side population of the recipient," PLoS One, vol. 7, no. 1, article e30260, 2012.

[16] I. Cervelló, C. Gil-Sanchis, X. Santamaría et al., "Human $\mathrm{CD}_{133^{+}}$bone marrow-derived stem cells promote endometrial proliferation in a murine model of Asherman syndrome," Fertil Steril, vol. 104, no. 6, pp. 1552-1560.e3, 2015.

[17] V. Letouzey, K. S. Tan, J. A. Deane et al., "Isolation and characterisation of mesenchymal stem/stromal cells in the ovine endometrium," PLoS One, vol. 10, no. 5, article e0127531, 2015.

[18] X. Lu, J. Cui, L. Cui et al., "The effects of human umbilical cord-derived mesenchymal stem cell transplantation on endometrial receptivity are associated with Th1/Th2 balance change and uNK cell expression of uterine in autoimmune premature ovarian failure mice," Stem Cell Research \& Therapy, vol. 10, no. 1, p. 214, 2019.

[19] L. N. Xu, N. Lin, B. N. Xu, J. B. Li, and S. Q. Chen, "Effect of human umbilical cord mesenchymal stem cells on endometriotic cell proliferation and apoptosis," Genetics and Molecular Research, vol. 14, no. 4, pp. 16553-16561, 2015.

[20] X. Yang, M. Zhang, Y. Zhang, W. Li, and B. Yang, "Mesenchymal stem cells derived from Wharton jelly of the human umbilical cord ameliorate damage to human endometrial stromal cells," Fertility and Sterility, vol. 96, no. 4, pp. 10291036.e4, 2011.

[21] S. A. Abbah, K. Spanoudes, T. O’Brien, A. Pandit, and D. I. Zeugolis, "Assessment of stem cell carriers for tendon tissue engineering in pre-clinical models," Stem Cell Research \& Therapy, vol. 5, no. 2, p. 38, 2014.

[22] L. Aubert, M. Dubus, H. Rammal et al., "Collagen-based medical device as a stem cell carrier for regenerative medicine," International Journal of Molecular Sciences, vol. 18, no. 10, p. 2210, 2017.

[23] M. Razzaghi, A. Rahavian, M. Fallah Karkan, F. Allameh, S. Ghiasy, and B. Javanmard, "Use of human amniotic membrane repair of anterior urethral defect: first clinical report," International Journal of Urology, vol. 27, no. 7, pp. 605-609, 2020. 
[24] B. Farhadihosseinabadi, M. Farahani, T. Tayebi et al., "Amniotic membrane and its epithelial and mesenchymal stem cells as an appropriate source for skin tissue engineering and regenerative medicine," Artificial Cells, Nanomedicine, and Biotechnology, vol. 46, Supplement 2, pp. 431-440, 2018.

[25] K. Jirsova and G. L. A. Jones, “Amniotic membrane in ophthalmology: properties, preparation, storage and indications for grafting-a review," Cell and Tissue Banking, vol. 18, no. 2, pp. 193-204, 2017.

[26] T. G. Kim, K. Do Ki, M. K. Lee, J. W. So, S. K. Chung, and J. Kang, "Comparison of cytokine expression and ultrastructural alterations in fresh-frozen and dried electron beamirradiated human amniotic membrane and chorion," Cell and Tissue Banking, vol. 20, no. 2, pp. 163-172, 2019.

[27] H. Niknejad, T. Deihim, M. Solati-Hashjin, and H. Peirovi, "The effects of preservation procedures on amniotic membrane's ability to serve as a substrate for cultivation of endothelial cells," Cryobiology, vol. 63, no. 3, pp. 145-151, 2011.

[28] X. Yang, Y. Liu, T. C. Li et al., "Durations of intrauterine balloon therapy and adhesion reformation after hysteroscopic adhesiolysis: a randomized controlled trial," Reproductive Biomedicine Online, vol. 40, no. 4, pp. 539-546, 2020.

[29] S. Orman, S. Yol, H. Uzun, A. B. Ceyran, and F. Eyüboğlu, "Effect of acellular amniotic membrane matrix patch on healing of cut surface after sleeve gastrectomy in rats," Journal of Investigative Surgery, vol. 33, no. 1, pp. 97-105, 2020.

[30] M. Kang, S. Choi, and A. R. Cho Lee, "Effect of freeze dried bovine amniotic membrane extract on full thickness wound healing," Archives of Pharmacal Research, vol. 36, no. 4, pp. 472-478, 2013.

[31] X. Chen, J. Sun, X. Li, L. Mao, L. Cui, and W. Bai, “Transplantation of oral mucosal epithelial cells seeded on decellularized and lyophilized amniotic membrane for the regeneration of injured endometrium," Stem Cell Research \& Therapy, vol. 10, no. 1, p. 107, 2019.

[32] G. Işık, M. Oktem, I. Guler et al., "The impact of granulocyte colony-stimulating factor (G-CSF) on thin endometrium of an animal model with rats," Gynecological Endocrinology, vol. 37, no. 5, pp. 438-445, 2021.

[33] C. B. Nagori, S. Y. Panchal, and H. Patel, "Endometrial regeneration using autologous adult stem cells followed by conception by In Vitro fertilization in a patient of severe Asherman's syndrome," J Hum Reprod Sci, vol. 4, no. 1, pp. 43-48, 2011.

[34] H. Masuda, T. Maruyama, C. E. Gargett et al., "Endometrial side population cells: potential adult stem/progenitor cells in endometrium," Biology of Reproduction, vol. 93, no. 4, p. 84, 2015.

[35] K. Miyazaki, T. Maruyama, H. Masuda et al., "Stem cell-like differentiation potentials of endometrial side population cells as revealed by a newly developed in vivo endometrial stem cell assay," PLoS One, vol. 7, no. 12, article e50749, 2012.

[36] R. Sarugaser, D. Lickorish, D. Baksh, M. M. Hosseini, and J. E. Davies, "Human umbilical cord perivascular (HUCPV) cells: a source of mesenchymal progenitors," Stem Cells, vol. 23, no. 2, pp. 220-229, 2005.

[37] D. Baksh, R. Yao, and R. S. Tuan, “Comparison of proliferative and multilineage differentiation potential of human mesenchymal stem cells derived from umbilical cord and bone marrow," Stem Cells, vol. 25, no. 6, pp. 1384-1392, 2007.

[38] Y. Yang, M. Pang, C. Du et al., "Repeated subarachnoid administrations of allogeneic human umbilical cord mesen- chymal stem cells for spinal cord injury: a phase $1 / 2$ pilot study," Cytotherapy, vol. 23, no. 1, pp. 57-64, 2021.

[39] X. Wu, Z. Ma, and D. Wu, "Derivation of clinical-grade mesenchymal stromal cells from umbilical cord under chemically defined culture condition - platform for future clinical application," Cytotherapy, vol. 22, no. 7, pp. 377-387, 2020.

[40] Z. Li, H. Qin, Z. Feng et al., "Human umbilical cord mesenchymal stem cell-loaded amniotic membrane for the repair of radial nerve injury," Neural Regeneration Research, vol. 8, no. 36, pp. 3441-3448, 2013.

[41] Y. Cao, H. Sun, H. Zhu et al., "Allogeneic cell therapy using umbilical cord MSCs on collagen scaffolds for patients with recurrent uterine adhesion: a phase I clinical trial," Stem Cell Research \& Therapy, vol. 9, no. 1, p. 192, 2018.

[42] L. Xu, L. Ding, L. Wang et al., "Umbilical cord-derived mesenchymal stem cells on scaffolds facilitate collagen degradation via upregulation of MMP-9 in rat uterine scars," Stem Cell Research \& Therapy, vol. 8, no. 1, p. 84, 2017.

[43] G. Zhao, Y. Cao, X. Zhu et al., "Transplantation of collagen scaffold with autologous bone marrow mononuclear cells promotes functional endometrium reconstruction via downregulating $\triangle \mathrm{Np} 63$ expression in Asherman's syndrome," Science China. Life Sciences, vol. 60, no. 4, pp. 404-416, 2017.

[44] L. Xin, X. Lin, Y. Pan et al., "A collagen scaffold loaded with human umbilical cord-derived mesenchymal stem cells facilitates endometrial regeneration and restores fertility," Acta Biomaterialia, vol. 92, pp. 160-171, 2019.

[45] I. Ullah, R. B. Subbarao, and G. J. Rho, "Human mesenchymal stem cells - current trends and future prospective," Bioscience Reports, vol. 35, no. 2, 2015.

[46] Q. Shi, J. W. Gao, Y. Jiang et al., "Differentiation of human umbilical cord Wharton's jelly-derived mesenchymal stem cells into endometrial cells," Stem Cell Research \& Therapy, vol. 8, no. 1, p. 246, 2017.

[47] X. M. Chen, Q. C. Kan, F. Wang et al., "Chromosome dynamic changes in two cultured Chinese human embryonic stem cell lines: single nucleotide polymorphism, copy number variation and loss of heterozygosity," Journal of Cellular Biochemistry, vol. 113, no. 11, pp. 3520-3527, 2012.

[48] H. Fu, L. Wang, J. Wang et al., "Dioxin and AHR impairs mesoderm gene expression and cardiac differentiation in human embryonic stem cells," Science of the Total Environment, vol. 651, Part 1, pp. 1038-1046, 2019.

[49] I. N. Stocchero, N. F. Lizier, R. F. Stelini et al., "A reliable stem cell carrier: an experimental study in Wistar rats," Aesthetic Plastic Surgery, vol. 43, no. 5, pp. 1353-1361, 2019.

[50] S. Shirian, S. Ebrahimi-Barough, H. Saberi et al., "Comparison of capability of human bone marrow mesenchymal stem cells and endometrial stem cells to differentiate into motor neurons on electrospun Poly( $\varepsilon$-caprolactone) scaffold," Molecular Neurobiology, vol. 53, no. 8, pp. 5278-5287, 2016.

[51] C. Wu, Y. Dong, Y. Li, and H. Liu, "The efficacy of amniotic membrane-mediated sequential double-barrier therapy for the treatment of postoperative intrauterine adhesions," Medicine (Baltimore), vol. 100, no. 15, article e25416, 2021.

[52] J. I. Coon, S. Jain, K. M. Sepuru et al., "Lyophilization of human amniotic fluid is feasible without affecting biological activity," Pediatric Research, vol. 87, no. 5, pp. 847-852, 2020.

[53] M. Fenelon, M. Etchebarne, R. Siadous et al., "Assessment of fresh and preserved amniotic membrane for guided bone 
regeneration in mice," Journal of Biomedical Materials Research Part A, vol. 108, no. 10, pp. 2044-2056, 2020.

[54] H. Thomasen, M. Pauklin, K. P. Steuhl, and D. Meller, "Comparison of cryopreserved and air-dried human amniotic membrane for ophthalmologic applications," Graefe's Archive for Clinical and Experimental Ophthalmology, vol. 247, no. 12, pp. 1691-1700, 2009.

[55] C. L. Allen, G. Clare, E. A. Stewart et al., "Augmented dried versus cryopreserved amniotic membrane as an ocular surface dressing," PLoS One, vol. 8, no. 10, article e78441, 2013.

[56] <ijcep0006-1343.pdf>.

[57] N. I. Chaudhary, G. J. Roth, F. Hilberg et al., "Inhibition of PDGF, VEGF and FGF signalling attenuates fibrosis," The European Respiratory Journal, vol. 29, no. 5, pp. 976-985, 2007.

[58] N. Ebrahim, O. Mostafa, R. E. el Dosoky et al., "Human mesenchymal stem cell-derived extracellular vesicles/estrogen combined therapy safely ameliorates experimentally induced intrauterine adhesions in a female rat model," Stem Cell Research \& Therapy, vol. 9, no. 1, p. 175, 2018.

[59] J. X. Chen, X. J. Yi, P. L. Gu, and S. X. Gao, "The role of KDR in intrauterine adhesions may involve the TGF- $\beta 1 /$ Smads signaling pathway," Brazilian Journal of Medical and Biological Research, vol. 52, no. 10, article e8324, 2019.

[60] X. Xue, Q. Chen, G. Zhao, J. Y. Zhao, Z. Duan, and P. S. Zheng, "The overexpression of TGF- $\beta$ and CCN2 in intrauterine adhesions involves the NF- $\kappa \mathrm{B}$ signaling pathway," PLoS One, vol. 10, no. 12, article e0146159, 2015.

[61] O. Taskin, A. Onoglu, M. Inal et al., "Long-term histopathologic and morphologic changes after thermal endometrial ablation," The Journal of the American Association of Gynecologic Laparoscopists, vol. 9, no. 2, pp. 186-190, 2002.

[62] K. Musiał and D. Zwolińska, "Matrix metalloproteinases (MMP-2,9) and their tissue inhibitors (TIMP-1,2) as novel markers of stress response and atherogenesis in children with chronic kidney disease (CKD) on conservative treatment," Cell Stress \& Chaperones, vol. 16, no. 1, pp. 97-103, 2011.

[63] H. Zhao, Y. Dong, X. Tian et al., "Matrix metalloproteinases contribute to kidney fibrosis in chronic kidney diseases," World J Nephrol, vol. 2, no. 3, pp. 84-89, 2013.

[64] L. Zhang, Y. Li, C. Y. Guan et al., "Therapeutic effect of human umbilical cord-derived mesenchymal stem cells on injured rat endometrium during its chronic phase," Stem Cell Research \& Therapy, vol. 9, no. 1, p. 36, 2018.

[65] A. Z. Szóstek-Mioduchowska, A. Baclawska, K. Okuda, and D. J. Skarzynski, "Effect of proinflammatory cytokines on endometrial collagen and metallopeptidase expression during the course of equine endometrosis," Cytokine, vol. 123, p. 154767, 2019.

[66] I. Granot, Y. Gnainsky, and N. Dekel, "Endometrial inflammation and effect on implantation improvement and pregnancy outcome," Reproduction, vol. 144, no. 6, pp. 661-668, 2012.

[67] M. Persson, C. Ekerfelt, B. Jablonowska et al., "Immunological status in patients undergoing In Vitro fertilisation: responses to hormone treatment and relationship to outcome," Journal of Reproductive Immunology, vol. 96, no. 1-2, pp. 58-67, 2012. 